\title{
Sensibilidade do Ouriço Arbacia lixula (Echinodermata: Echinoidea) em Testes de Toxicidade
}

\author{
M. V. Máximo, ${ }^{*}$ L. S. M. Mottola \& C. Resgalla JR. \\ CTTMar/UNIVALI, C.P. 360, CEP 88.302-202, Itajaí, SC, Brasil
}

(Received July 30, 2007; Accepted March 13, 2008)

\begin{abstract}
RESUMO
O presente trabalho investigou o ouriço Arbacia lixula quanto ao seu tempo de desenvolvimento embrio-larval, tolerância do desenvolvimento em diferentes salinidades e temperaturas da água de manutenção, sua repetitividade diante de substâncias de referência para uso em testes de toxicidade e sua sensibilidade em comparação com outras espécies de ouriços normal-mente utilizadas no Brasil. $\mathrm{O}$ desenvolvimento embrionário de A. lixula a $25^{\circ} \mathrm{C}$ foi rápido, atingindo a fase de larva pluteus em menos de 24 horas, não necessitando prolongar o encerramento dos experimentos, entretanto, apresenta algumas desvantagens, como uma membrana de fecundação pouco nítida e, freqüentemente, um percentual de fecundação entre 70 e $80 \%$. Nos experimentos de viabilidade dos embriões em diferentes salinidades e temperaturas demonstrou ampla tolerância, com desenvolvimento normal de $24 \mathrm{~h}$ para salinidades entre 29 e 39 e de $20 \mathrm{~h}$ para uma temperatura de $30^{\circ} \mathrm{C}$. Os testes de toxicidade realizados com substâncias de referência resultaram em valores de coeficientes de variação inferiores a $30 \%$ para cromo e zinco, demonstrando a repetitividade dos testes. Quando comparada com outras espécies de ouriço-do-mar (Lytechinus variegatus e Echinometra lucunter), A. lixula apresenta sensibilidade na mesma ordem de grandeza e resultados similares para amostras ambientais (elutriato de sedimentos).
\end{abstract}

Palavras-chave: Arbacia lixula, testes de toxicidade, sensibilidade, substâncias de referência.

\section{ABSTRACT}

\section{Sensitivity of the sea urchin Arbacia lixula (Echinodermata: Echinoidea) in toxicity tests}

This study investigates the sea urchin Arbacia lixula in terms of embryonic and larval development time, development tolerance in different salinities and maintenance water temperatures, its repeatability in the presence of reference toxicants used in toxicity tests, and its sensitivity in comparison with other species of sea urchin normally used in Brazil. The embryonic development of $A$. lixula at $25^{\circ} \mathrm{C}$ rapidly reached the larval stage pluteus in less than 24 hours, therefore it was not necessary to extend the period of the experiments. However, it presents some disadvantages such as a fertilization membrane that is not very clear, and often with a fertilization rate from 70 to $80 \%$. The experiments to determine the viability of the embryos in different salinities and temperatures demonstrated a wide tolerance, with a normal development of $24 \mathrm{~h}$ between the salinities of 29 and 39 and $20 \mathrm{~h}$ for $30{ }^{\circ} \mathrm{C}$ of temperature. The toxicity tests carried out with the reference toxicant resulted in values for variation coefficients lower than $30 \%$ for chromium and zinc, demonstrating that the tests are repeateable. When compared with other sea-urchin species (Lytechinus variegatus and Echinometra lucunter), A. lixula presented sensitivity of the same order and scale, and similar results were obtained for the environmental samples (sediment elutriate).

Key words: Arbacia lixula, toxicity tests, sensitivity, reference toxicant.

*Corresponding author: Marcus Vinicius Máximo, e-mail: mvmaximo@gmail.com. 


\section{INTRODUÇÃO}

Os testes de toxicidade embrio-larval de ouriços têm sido amplamente utilizados no mundo desde a década de 1920 devido principalmente a facilidades de execução, sensibilidade e reprodutibilidade (Dinnel et al., 1988). Em vários países, diferentes espécies têm sido adequadas a metodologias para a realização de estudos de impacto ambiental para fins litigiosos e de regulamentação. Exemplos clássicos são apresentados por Environment Canadá (1992) e Standard Methods (Clesceri et al., 1998) com várias espécies de ouriços. A própria USEPA (2002), que apresenta apenas uma espécie para uso em testes de toxicidade, permite a ampliação para outras espécies não listadas.

Recentemente no Brasil, a Associação Brasileira de Normas Técnicas (ABNT, 2006) apresentou a norma de execução de testes de toxicidade com ouriços Lytechinus variegatus e Echinometra lucunter. Apesar da importância na regulamentação dos procedimentos de execução dos ensaios, originalmente estabelecidos pelo protocolo da CETESB (1992), essa norma limita a aplicação para outras espécies de ocorrência local, restringindo seu uso para a ampla costa brasileira.

Tem sido freqüentemente destacado por diferentes autores que a sensibilidade de espécies pertencentes ao mesmo grupo taxonômico não apresenta variações significativas que possam justificar a eleição de apenas uma ou duas espécies para uso como organismos-teste (Environment Canada, 1992; His et al., 1999; Resgalla Jr. \& Laitano, 2002). Para Echinodermos, Laitano et al. (no prelo) compararam a sensibilidade da bolacha-do-mar Mellita quinquiesperforata com as demais espécies de ouriços e observou que a sensibilidade entre elas foi muito similar em base de experimentos com o uso de substâncias de referência.

$\mathrm{Na}$ costa brasileira existe uma diversidade de 329 espécies de Echinodermatas (Tommasi, 1999) que possibilitam o seu uso em testes de toxicidade. Entre as espécies de ouriços, Arbacia lixula (Echinodermata: Echinoidea) destaca-se pela alta abundância em águas rasas. Pertence à família Arbaciidae com carapaça avermelhada ou negra, espinhos finos e muitas vezes com as pontas esbranquiçadas. Ocorre na costa Atlântica da América do Sul, da Venezuela até a foz do rio da Prata. É uma espécie litoral de costa rochosa que se distribui até $50 \mathrm{~m}$ de profundidade. Não é escavadora e alimenta-se de macroalgas (Tommasi, 1966).

Estudos com o uso de A. lixula como organismo-teste têm sido registrados desde a década de 1960 pelos trabalhos de Soyer (1963) e Castagna (1976). No Brasil, somente o relatório da CETESB (1990) apresenta uma tentativa de sua utilização, mas sem resultados conclusivos.

No presente trabalho, essa espécie foi investigada quanto ao seu tempo de desenvolvimento embrio-larval, tolerância às variáveis físico-químicas da água de manutenção e sensibilidade e repetitividade diante de substâncias de referência para o seu uso em testes de toxicidade em comparação com outras espécies de ouriços normalmente utilizadas no Brasil.

\section{MATERIAL E MÉTODOS}

\section{Obtenção de organismos}

Trinta indivíduos adultos do ouriço Arbacia lixula foram coletados na praia da Paciência, na enseada da Armação do Itapocoroy, no município de Penha, litoral norte de Santa Catarina, através de mergulho em apnéia. Após a coleta, os organismos foram mantidos no Laboratório de Ecotoxicologia (CTTMar/Univali) em aquários de 20 litros, com salinidade de 32 , fotoperíodo $12: 12$ h e a $22^{\circ} \mathrm{C}$, por um período máximo de 48 horas antes dos experimentos.

\section{Indução a desova, coleta dos gametas e fertilização}

A indução para a liberação dos gametas foi realizada mediante injeção de cloreto de potássio a $0,5 \mathrm{M}(\mathrm{KCl})$ na região perioral (inferior) segundo norma da ABNT (2006). Os gametas masculinos distintos por sua cor branca foram coletados com pipeta de Pasteur e adicionados em becker de $20 \mathrm{~mL}$ sobre gelo. Os gametas femininos (cor avermelhada) foram liberados em água do mar em um becker de $200 \mathrm{~mL}$. A fertilização consistiu na adição de uma alíquota de solução espermática preparada com a diluição de $0,5 \mathrm{~mL}$ de espermatozóides em $24,5 \mathrm{~mL}$ de água do mar filtrada aos ovócitos. O controle da fertilização destes foi feito pela observação em microscópio óptico (100•) do surgimento de uma membrana externa de fecundação.

\section{Tempo de desenvolvimento embrio-larval}

Para o acompanhamento do desenvolvimento do ovo até larva pluteus, foram adicionados 50 ovos $\mathrm{mL}^{-1} \mathrm{em}$ frasco-teste de $15 \mathrm{~mL}$ contendo $10 \mathrm{~mL}$ de água do mar filtrada a 30 e incubadas a $25^{\circ} \mathrm{C}$ com fotoperíodo de $12: 12$. Os organismos foram fixados em formol a $4 \%$ em diferentes tempos para o registro de cada estágio de desenvolvimento por um período máximo de 24 horas.

\section{Tolerância a diferentes salinidades e temperaturas}

Experimentos de tolerância dos embriões de A. lixula consistiram na exposição de ovos em diferentes salinidades $(25$ a 40$)$ e temperaturas $\left(15,20,25\right.$ e $\left.30^{\circ} \mathrm{C}\right)$. Os ensaios foram constituídos por quatro replicatas para cada tratamento. Os testes de salinidade foram conduzidos à temperatura constante de $25^{\circ} \mathrm{C}$ e os de temperatura, à salinidade constante de 30, ambos com fotoperíodo de 12:12. Os experimentos foram encerrados com a adição de formol a 4\% após 24 horas. Para cada replicata foram quantificadas 100 larvas divididas em normais e alteradas, segundo os critérios recomendados pela ABNT (2006), em câmaras de Sedgewick Rafter.

\section{Testes de toxicidade com substâncias de referência}

Foram executados testes de toxicidade segundo norma da ABNT (2006), utilizando quatro substâncias de referência: sulfato de cobre $\left(\mathrm{CuSO}_{4} \cdot 5 \mathrm{H}_{2} \mathrm{O}\right)$, sulfato de zinco $\left(\mathrm{ZnSO}_{4} \cdot 7 \mathrm{H}_{2} \mathrm{O}\right)$, dicromato de potássio $\left(\mathrm{K}_{2} \mathrm{Cr}_{2} \mathrm{O}_{7}\right)$ e dodecil sulfato de sódio [DSS $\left.\left(\mathrm{C}_{12} \mathrm{H}_{25} \mathrm{NaO}_{4} \mathrm{~S}\right)\right]$. Todos os experimentos foram executados 
em seis concentrações mais o controle, quatro replicatas por concentração, água de diluição (água do mar natural) a $30 \%$, temperatura de $25^{\circ} \mathrm{C}$ e fotoperíodo de $12: 12$. Os procedimentos de encerramento e quantificação das larvas seguiram a metodo-logia recomendada pela ABNT (2006).

\section{Comparações com Lytechinus variegatus para amostras ambientais}

A sensibilidade de $A$. lixula foi comparada com a espécie Lytechinus variegatus utilizando-se elutriatos a $100 \%$ obtidos de amostras de sedimento do rio Itajaí-açu estudadas por Silveira (2002). Os elutriatos foram preparados na proporção de 1:4 (sedimento:água do mar) por deslocamento de volume com agitação de 30 minutos, decantação e filtragem do sobrenadante. Para essa comparação foram ainda realizados testes de toxicidade com cloreto de amônia $\left(\mathrm{NH}_{4} \mathrm{Cl}\right)$ constituinte que normalmente explica a toxicidade dos sedimentos para o rio Itajaí-açu. Os experimentos com o elutriato (a $100 \%$ ), cloreto de amônia (com diluições) e a espécie $L$. variegatus foram executados como os descritos para A. lixula utilizando as substâncias de referência.
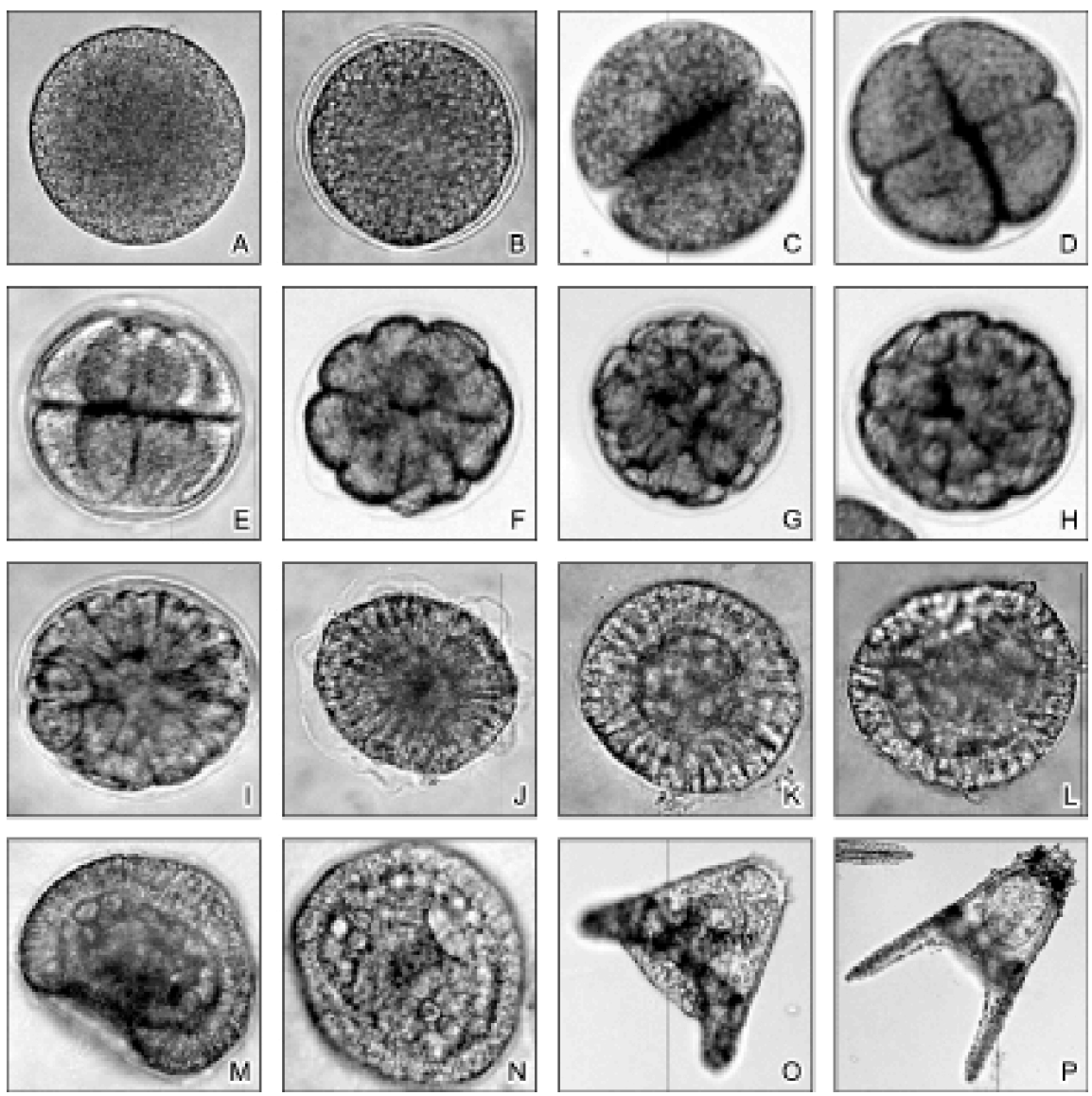

Figura 1 - Desenvolvimento embrio-larval do ouriço Arbacia lixula a $25^{\circ} \mathrm{C}$ (e tempo de desenvolvimento acumulado). Sendo: A: óvulo; B: ovo com membrana de fertilização; C: estágio de 2 células (50 minutos); D: estágio de 4 células (1:30 hora; E: estágio de 8 células (1:40 hora); F: estágio de 16 células (2:10 horas); G: estágio de 32 células ( $2: 40$ horas); H: mórula (3:30 horas); I: blástula (4:00 horas); J: blástula natante (5:30 horas); K: blástula com mesênquima desenvolvido (7:00 horas); L: gástrula recém-formada (11:00 horas); M: gástrula plenamente desenvolvida (12:00 horas); N: estágio de prisma (14:00 horas); O: estágio entre prisma e pluteus (19:00 horas); P: estágio de larva pluteus (22:00 horas). 


\section{Tolerância embrio-larval de Arbacia lixula às variações de salinidade e temperatura}

Os embriões e larvas de $A$. lixula apresentaram ampla tolerância à temperatura de cultivo, tendo desenvolvimento normal de 24 horas entre 20 e $30^{\circ} \mathrm{C}$ (Tabela 1 ). A $15^{\circ} \mathrm{C}$ o desenvolvimento normal até a larva pluteus ocorre somente em 120 horas, e em tempos inferiores os percentuais de efeito foram superiores a $20 \%$. Quanto às variações de salinidade, embriões e larvas apresentaram desenvolvimento normal (> 80\%) entre as salinidades de 29 a 39 (Figura 2). Esta ampla tolerância da espécie é um fator positivo no uso de testes de toxicidade, permitindo ampliar o leque de aplicação em diferentes condições experimentais.

\section{Sensibilidade e carta-controle de tendência}

Os resultados dos testes de toxicidade com diferentes substâncias de referência estão representados na Tabela 2 . Para os metais cromo e zinco, os valores dos coeficientes de variação (CV) foram inferiores a 30\%, demonstrando repetitividade dos testes. Esses resultados somados à cartacontrole de tendência (Figura 3) para o cromo confirmam a adequação do uso dessa espécie como organismo teste.

Em comparação com espécies utilizadas em normas da ABNT (Lytechinus variegatus e Echinometra lucunter), A. lixula apresenta sensibilidade na mesma ordem de grandeza e dentro do intervalo de variação das espécies normalmente utilizadas e recomendadas para os testes realizados no Brasil (Tabela 3). Destaca-se, além disso, uma escassez de informações de sensibilidade para E. lucunter, apesar de ter sido recentemente incluída nas normas da ABNT (2006).

\section{Comparação de sensibilidade entre Arbacia lixula e Lytechinus variegatus para amostras ambientais}

Estudos posteriores ao de Laitano \& Resgalla Jr. (2000) sobre a qualidade do sedimento do rio Itajaí-açu têm confirmado que a toxicidade do sedimento desse ambiente está, na grande maioria dos casos, associada às altas concentrações de amônia não ionizada (dados não publicados). No monitoramento da toxicidade do sedimento do rio tem sido empregada a espécie $A$. lixula como organismo-teste, cuja sensibilidade é a mesma em relação a $L$. variegatus, tanto para o amônio total como para amostras do sedimento do rio (Figura 4).

Independente do constituinte tóxico presente nas amostras do sedimento do rio Itajaí-açu, o uso de $A$. lixula pode ser considerado válido para a resolução CONAMA 344/04 em programas de monitoramento de material dragado em regiões portuárias, mesmo que o sedimento apresente alta diversidade de contaminantes.

Tabela 1 - Tempo de desenvolvimento (horas) e porcentagem de efeito médio (\%) observados para larvas do ouriço Arbacia lixula cultivados em diferentes temperaturas.

\begin{tabular}{ccc}
\hline $\begin{array}{c}\text { Temperatura } \\
\left({ }^{\circ} \mathbf{C}\right)\end{array}$ & $\begin{array}{c}\text { Tempo de } \\
\text { desenvolvimento } \\
\text { (horas) }\end{array}$ & $\begin{array}{c}\text { Porcentagem de } \\
\text { efeito } \\
(\%)\end{array}$ \\
\hline 15 & 24 & 100,00 \\
& 120 & 13,25 \\
20 & & 0,50 \\
30 & 24 & 1,00 \\
& & 3,25 \\
\hline
\end{tabular}

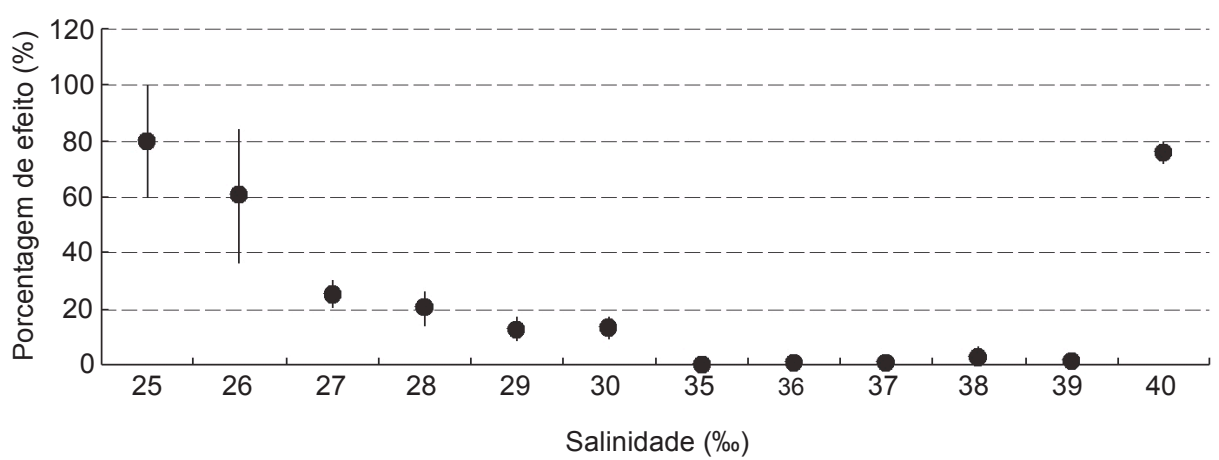

Figura 2 - Valores médios (ponto) e desvio-padrão (linha vertical) dos percentuais de efeito (\%) observados para larvas de Arbacia lixula cultivados em diferentes salinidades por 24 horas. 
Tabela 2 - Valores de $\mathrm{CE}_{50}\left(\propto \mathrm{g} . \mathrm{L}^{-1}\right)$ para diferentes substâncias de referência em testes de toxicidade utilizando a fase embrio-larval de Arbacia lixula.

\begin{tabular}{|c|c|c|c|c|c|}
\hline \multirow{2}{*}{ Substância } & \multicolumn{3}{|c|}{$\mathrm{CE}_{50}\left(\propto \mathrm{g} . \mathrm{L}^{-1}\right)$} & \multirow{2}{*}{$\begin{array}{c}\text { Número de } \\
\text { testes (n) }\end{array}$} & \multirow{2}{*}{$\begin{array}{l}\text { Coeficiente de } \\
\text { variação }(\mathrm{CV})\end{array}$} \\
\hline & Mínimo & Máximo & Médio & & \\
\hline Cromo & 1430,0 & 2620,0 & 2089,0 & 10 & $21,4 \%$ \\
\hline Zinco & 29,0 & 54,0 & 42,0 & 6 & $26,8 \%$ \\
\hline Cobre & 46,0 & 53,0 & 49,0 & 2 & - \\
\hline DSS & & 1250,0 & & 1 & - \\
\hline
\end{tabular}

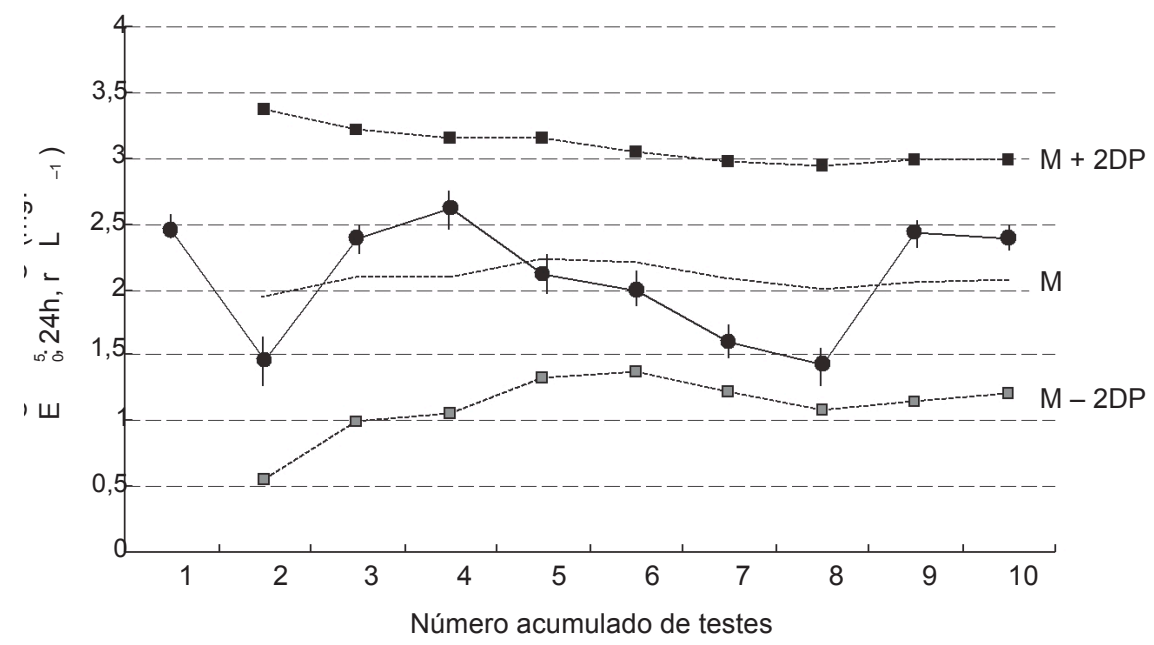

Figura 3 - Carta-controle de tendência para o cromo $\left(\mathrm{CE}_{50}-\mathrm{mg} . \mathrm{L}^{-1}\right)$ em testes de toxicidade embrio-larval de Arbacia lixula. Sendo: $\mathrm{M}=$ média e DP = desvio-padrão.

Tabela 3 - Intervalo de variação dos valores de $\mathrm{CE}_{50}\left(\propto \mathrm{g} . \mathrm{L}^{-1}\right)$ de diferentes substâncias de referência para as espécies de ouriços-do-mar normalmente utilizadas em testes embrio-larval no Brasil.

\begin{tabular}{cccc}
\hline Substância & Arbacia lixula & Lytechinus variegatus & Echinometra lucunter \\
\hline Cromo & $1.430,0-2.620,0$ & $3.990,0$ & - \\
Zinco & $29,9-54,0$ & $30,0-140,0$ & - \\
Cobre & $46,0-53,0$ & $21,7-45,9$ & $19,9-24,0$ \\
DSS & 1250,0 & $1.700,0-3.600,0$ & $1.200,0-3.000,0$ \\
& & Nipper et al. (1993); Rumbold \& & \\
Autores & Presente trabalho & Snedaker (1997); Resgalla \& & Rumbold \& Snedaker (1997) \\
& & Laitano (2002) & \\
\hline
\end{tabular}



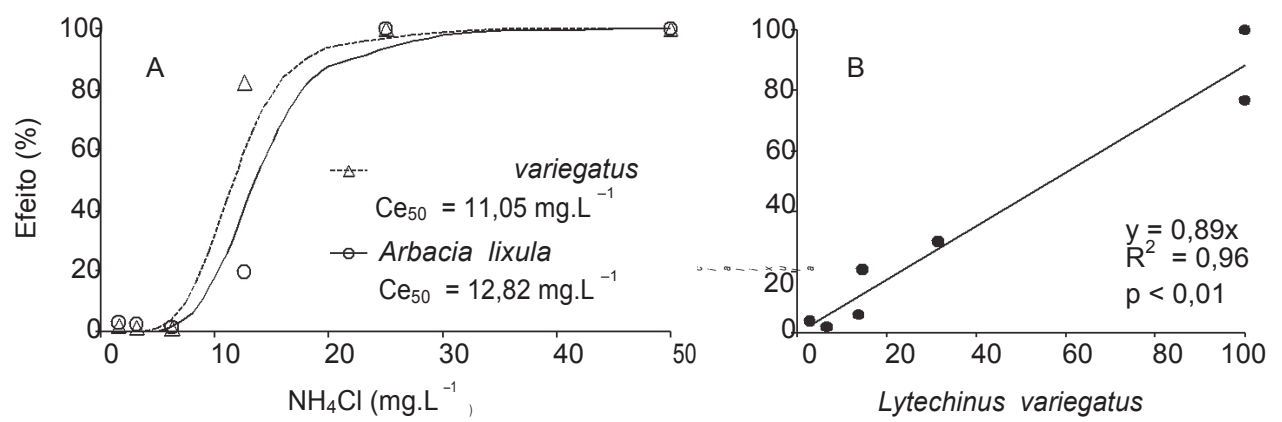

Figura 4 - Comparação da sensibilidade de Lytechinus variegatus e Arbacia lixula em (A) testes de toxicidade sob efeito do cloreto de amônia $\left(\mathrm{NH}_{4} \mathrm{Cl}\right)$ e (B) para amostras de elutriato obtidas do sedimento do rio Itajaí-açu (SC).

\section{CONCLUSÕES}

A espécie de ouriço Arbacia lixula apresenta alta abundância em águas rasas da costa brasileira, aparentemente sem sazonalidade no seu ciclo reprodutivo. Em razão dessas características sugere-se seu uso em testes de toxicidade embrio-larval. Os procedimentos para a execução dos experimentos são os mesmos adotados para espécies descritas na norma ABNT (2006), apresentando, entretanto, baixa visualização de sua membrana de fecundação e um percentual de fecundação normalmente entre 70 e $80 \%$. Por outro lado, a repetitividade dos ensaios assim como a sua sensibilidade, tanto diante de substâncias de referência quanto para amostras ambientais, demonstradas neste trabalho, permitem acrescentála à lista de espécies de ouriços de uso em testes de toxicidade embrio-larval no Brasil.

\section{REFERÊNCIAS BIBLIOGRÁFICAS}

ABNT, 2006, ABNT/NBR15350 - Ecotoxicologia aquática - Toxicidade crônica de curta duração - Método de ensaio com ouriço-do-mar (Echinodermata: Echinoidea). 17p.

CASTAGNA, A., 1976, Effect of mercury on egg development in the sea urchin Arbacia lixula. Boll. Pesca Piscic. Hidrobiol., 31(1/2):163-169.

CETESB, 1990, Desenvolvimento e implantação de testes de toxicidade com organismos marinhos - Relatório Anual 1989. Proj. 83.05.00. 38p.

CETESB, 1992, Teste de toxicidade crônica de curta duração com Lytechinus variegatus, Lamarck, 1816. Norma Técnica CETESB, L5.250.

CLESCERI, L. S., GREENBERG, A. E. \& EATON, A. D., 1998, Standard methods for the examination of water and wastewater. $20^{\text {th }}$ Edition, pp. 8-1, 8-140.

CONAMA, 2004, Resolução 344. 25 de março de 2004.

DINNEL, P., PAGANO, G. G. \& OSHIDA, P. S., 1988, A sea urchin test system for marine envirnmental monitoring. In: R. D. Burke, P. V. Mladenov, P. Lambert \& R. L. Parsley (eds.), International Echinoderm Conference, 6. Proceedings. Balkema, Rotterdam, pp. 611-619.
ENVIRONMENT CANADA, 1992, Biological test method: fertilization assay using echinoids (sea urchins and sand dollars). Env. Prot. Series. EPS 1/RM/27. 99p.

HIS, E., BEIRAS, R. \& SEAMAN, M. N. L., 1999, The assessment of marine pollution - bioassays with bivalve embryos and larvae. $A d v$. Mar. Biol., 37: 1-178.

LAITANO, K. \& RESGALlA Jr., C., 2000, Uso de testes de toxicidade com larvas de Arbacia lixula e juvenis de Metamysidopsis elongata atlantica na avaliação da qualidade do sedimentos dos rios Camboriú e Itajaí-Açu (Santa Catarina). In: E. L. G. Espíndola, C. M. R. Botta Paschoal, O. Rocha, M. B. C. Bohrer \& A. L. Oliveira-Neto (eds.), Ecotoxicologia. Perspectivas para o século XXI. RiMa, São Carlos, pp. $29-42$.

LAITANO, K. S., GONÇALVES, C. \& RESGALlA Jr., C., (no prelo), Estudo sobre a sensibilidade da bolacha-do-mar (Mellita quinquiesperforata) como organismo teste. J. Braz. Soc. Ecotoxicol.

NIPPER, M. G., PROSPERI, V. A. \& ZAMBONI, A. J., 1993, Toxicity testing with coastal species of southeastern Brazil. Echinoderm sperm and embryos. Bull. Environ. Contam. Toxicol., 50: 646-652.

RESGALLA Jr. \& LAITANO, K., 2002, Sensibilidade dos organismos marinhos utilizados em testes de toxicidade no Brasil. Notas Téc. Facimar, 6: 153-163.

RUMBOLD, D. G. \& SNEDAKER, S. C., 1997, Evaluation of bioassays to monitor surface microlayer toxicity in tropical marine waters. Arch. Environ. Contam. Toxicol., 32(2): 135-140.

SILVEIRA, R. M., 2002, Monitoramento da toxicidade do sedimento do rio Itajaí-açu e região costeira adjacente. Monografia, CTTMar/UNIVALI, 42p.

SOYER, J., 1963, Contribution a l'etude des effects biologiques du mercure et de l'argent dans l'eau de mer. J. Vie et Milieu, 14:36p.

TOMMASI, L. R., 1966, Lista dos equinóides recentes do Brasil. Cont. Inst. Oceanogr. Univ. São Paulo, 11: 1-50.

TOMMASI, L. R., 1999, Echinodermatas recentes e fósseis do Brasil. Base de Dados Tropical. Campinas. Disponível em: www.bdt.org.br/zoologia.

USEPA., 2002, Short-term methods for estimating the chronic toxicity of effluents and receiving waters to marine and estuarine organisms. Third Edition - EPA-821-R-02-014. 